\title{
Desbridamento de úlcera venosa com papaína associada à uréia
}

\author{
Solange Silveira*, Marcelo Alessandro Rigotti**, Adriano Menis Ferreira, D. Sc.***, \\ José Maria Pereira de Godoy, D.Sc.***
}

*Enfermeira, Especialista em Enfermagem Dermatológica, Enfermeira de Clínica Privada, ${ }^{* *}$ Enfermeiro Licenciado, ***Enfermeiro, Prof. do Departamento de Enfermagem da Universidade Federal de Mato Grosso do Sul-Três Lagoas,

****Médico, Prof. do Departamento de Cardiologia e Cirurgia Cardiovascular da Faculdade de Medicina de São José do Rio Preto - Famerp/SP

\section{Resumo \\ O objetivo do presente estudo de caso é apresentar a evolução do desbridamento de uma úlcera venosa com o uso da papaína associada à uréia. $\mathrm{O}$ desbridamento foi completo a partir do quarto dia, constatando-se que a terapia implementada agiu de forma eficaz e eficiente.}

Palavras-chave: úlcera varicosa, cicatrização de feridas, papaína, cuidados de enfermagem.

\section{Abstract \\ Venous ulcer debridement with papain and urea}

The present case study aimed to present the development of a venous ulcer debridement using papain with urea. Full debridement was achieved on the fourth day, showing the implemented therapy was efficient and effective.

Key-words: varicose ulcer, wound healing, papain, nursing care.

\section{Resumen \\ Desbridamiento de una úlcera venosa con papaína asociada a la urea}

El objetivo del presente estudio fue presentar la evolución del desbridamiento de una úlcera venosa con el uso de papaína asociada a la urea. El desbridamiento fue completo a partir del cuarto día, así se constató que la terapia implementada fue eficaz y eficiente.

Palabras-clave: úlcera varicosa, cicatrización de heridas, papaína, atención de enfermería. 


\section{Introdução}

O desbridamento de uma ferida é necessário para que a granulação e reepetelização ocorram. Envolve a remoção do tecido desvitalizado, contaminado e corpos estranhos [1]. É particularmente importante nas lesóes extensas, na presença de celulite e sépsis [1]. Pode ser realizado, principalmente, por procedimentos cirúrgico, mecânico, autolítico e enzimático. O desbridamento enzimático é utilizado nos pacientes que não toleram uma cirurgia e nas lesóes menores [2]. Diversos agentes debridantes, como as colagenases, fibrinolisina, desoxiribonuclease e a papaína são utilizadas. Essas substâncias têm permitido maior eficácia no desbridamento das feridas. Dentre elas, a papaína tem sido empregada de várias maneiras. Nos EUA ela é associada com a uréia e no Brasil em solução salina, na forma de creme ou gel [3-9].

O objetivo do presente estudo foi apresentar a evoluçáo do desbridamento de uma úlcera venosa com o uso da papaína associada à uréia.

\section{Relato de caso}

Paciente do sexo masculino, 56 anos, branco, com história de úlcera venosa, de aproximadamente $28 \mathrm{~cm}^{2}$ em membro inferior esquerdo, há 2 anos, a qual vinha recebendo terapia tópica diária alternando entre colagenase e óleo de girassol. Entretanto, a ferida apresentou uma rápida piora com formação de tecido desvitalizado, extravasamento de exsudato purulento e dor local, como mostra a Figura 1.

Figura 1 - Úlcera vascular com presença de tecido necrótico e esfacelo.

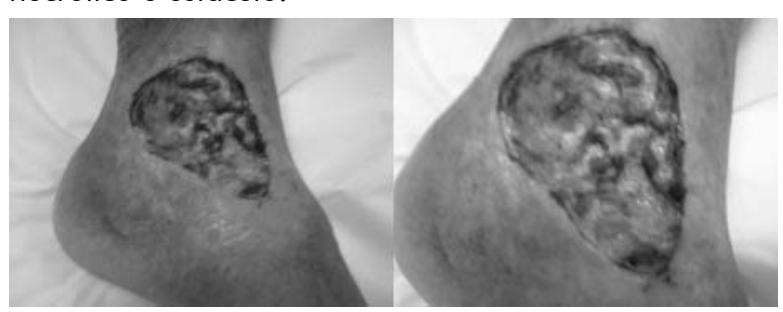

Em virtude do local da lesão e do paciente não apresentar envolvimento articular optou-se pelo desbridamento enzimático com papaína a $10 \%$ associada à uréia na mesma concentração e vitamina E duas vezes ao dia. Os curativos foram realizados utilizando-se a técnica limpa, que se caracteriza pela lavagem das mãos e utilização de luvas de procedi- mento. Já a limpeza da ferida foi realizada com soro fisiológico $0,9 \%$ em forma de jatos.

O desbridamento foi completo a partir do quarto dia, quando se optou pela mudança da cobertura para carboximetilcelulose associado a pectina. $\mathrm{O}$ paciente referiu que a papaína provocou uma sensação tolerável de queimação na primeira hora de aplicação, que foi eliminada após a mudança da terapia tópica.

\section{Resultados e discussão}

Nas feridas em que é detectada a presença de material desvitalizado é aconselhado o desbridamento. Sendo o enzimático uma opção segura e menos traumática, optou-se por utilizar a papaína associada à uréia em creme base não iônica.

Originada do látex das folhas e frutos do mamão verde adulto Carica papaya Linn, a papaína é uma enzima proteolítica muito empregada na indústria alimentícia, cosmética e farmacêutica [3], cujo sítio ativo é portador de um radical sulfidrila $(\mathrm{SH})$, pertencente ao aminoácido cisteína fundamental para sua atividade enzímica, tornando-se difícil sua associação com outro recurso terapêutico, visto que ela sofre oxidaçáo pela substituição do enxofre [5].

A papaína quebra qualquer proteína que contém resíduos de cisteína. Esta propriedade torna-a não seletiva, uma vez que muitas proteínas, incluindo fatores de crescimento, contêm resíduos de cisteína. O colágeno não contém resíduos de cisteína, portanto não sofre ação da papaína [10].

No Brasil, os primeiros estudos a utilizar a papaína no tratamento de feridas foram divulgados por Monetta que muito contribuiu para a popularização dessa substância [11]. Inicialmente, os extratos concentrados eram dissolvidos em soro fisiológico em concentraçóes variadas, geralmente em torno de 2,5\%. Em 1993 foi padronizado o gel de papaína [12], tornando-se mais uma opção no tratamento de feridas.

A associação com a uréia é comercializada nos EUA e relatada em vários estudos [4-7] que tem demonstrado que essa associação é duas vezes mais potente no desbridamento do que a papaína isoladamente [13]. Dentre os benefícios da uréia está o forte poder osmótico que ela apresenta [14], facilita a ação proteolítica da papaína alterando a estrutura tri-dimensional das proteínas e rompendo suas pontes de hidrogênio, bem como, expondo por ação solvente os ativadores da papaína. A uréia age, 
ainda, na redução das pontes disulfídicas, expondo os resíduos de cisteína que facilitam a ação terapêutica da papaína $[1,2,10]$.

Após o quarto dia de tratamento, observou-se desbridamento em toda a área da ferida, abundante presença de tecido de granulação permanecendo apenas pequenos pontos de esfacelo. Devido ao fato de o tecido de granulação ser apenas avaliado clinicamente, não se pode concluir que a presença desse tecido resultou da ação da papaína ou se tornou mais evidente após o desbridamento.

Figura 2 - Úlcera vascular após o quarto dia de uso da papaína com uréia e vitamina $E$. Nota-se presença de tecido de granulação e discretas áreas remanescentes de esfacelo.

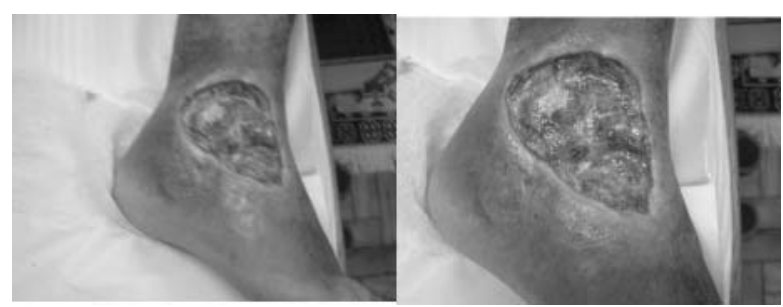

Uma vantagem da combinação da papaínauréia pode ser um desbridamento não específico dentro de uma grande faixa de $\mathrm{pH}(3.0-12.0)$. No entanto, talvez devido à característica não seletiva desta preparação, uma proeminente resposta inflamatória está associada com seu uso em feridas crônicas. Esta resposta inflamatória, juntamente com a quebra de componentes viáveis dentro do leito da ferida, é, provavelmente, a razão da dor associada ao uso destes agentes. Essas características, talvez possam explicar a dor relatada pelo paciente neste estudo. A fim de diminuir esse sintoma, associa-se à papaína o componente clorofila que age impedindo a aglutinação de eritrócitos, prevenindo a formação de trombos e deposiçáo de fibrina, e o tamponamento de vasos sanguíneos e linfáticos [10]. No entanto, não temos conhecimento da disponibilidade desta associação no Brasil.

\section{Conclusão}

No presente estudo a utilizaçáo da papaína na concentração de $10 \%$ associada à uréia e à vitamina E mostrou-se eficiente no desbridamento da lesão em curto período de tempo.

\section{Referências}

1. Bergstrom N, Bennett MA, Carlson CE, et al. Treatment of pressure ulcers. Clinical Practice Guideline no. 15. (AHCPR Publication No. 95-0652). Rockville (MD): US. Department of Health and Human Services, Public Heath Service, Agency for Health Care Policy and Research; 1994.

2. Kanj LF, Wilking SVB, Phillips T. Continuing Medical Education. J Am Acad Dermatol 1998;38517-36.

3. Miller JM. The interaction of papain urea, and water soluble chlorophyll in a proteolytic ointment for infected wounds. Surgery 1958;43:939-48.

4. Hermans LE, Rothman KF. Prevention, care and treatment of pressure (decubitus) ulcers in Intensive Care Units patients. J Intensive Care Med 1989;4:117-23.

5. Sibbald RG, Williamson D, Orsted HL, Campbell K, Keast D, Krasner D Sibbald D. Preparing the wound bed debridement, bacterial balance and moisture balance. Ostomy/Wound management 2000;46(11):1435.

6. Steed DL, Donohoe D, Webster MW, Lindsley L. Effect of extensive debridement and treatment on the healing of diabetic foot ulcers. J Am Coll Surg 1996;183:61-4.

7. Moneta L. O uso da papaína nos curativos feitos pela enfermagem. Rev Bras Enfermagem 1987;40(1):6673.

8. Masini E, Calamo MA. Uma forma de tratamento de lesóes cutâneas com papaína e sacarose. Rev Bras Clin Terap 1986;15:245-8.

9. Monetta L. Análise evolutiva do processo de cicatrização em úlceras diabéticas, de pressão e venosas com uso de papaína [dissertação]. Sáo Paulo: Escola de Enfermagem da Universidade de São Paulo; 1998.

10. Falanga V. Wound bed preparation and the role of enzymes: a case for multiple actions of therapeutic agents. Wound 2002;14(2):47-57.

11. Ferreira, AM, Oliveira, KA, Vieira LC, Rol, JL. Revisão de estudos clínicos de enfermagem: utilizaçáo de papaína para o tratamento de feridas. Rev Enfermagem UERJ 2005;13:382-9.

12. Velasco MVR. Desenvolvimento e padronização de gel contendo papaína para uso tópico. [Dissertação]. São Paulo: Faculdade de Ciências Farmacêuticas da Universidade de Sáo Paulo; 1993.

13. Silverstein P, Ruzicka FJ, Helmkamp GM, et al. In vitro evaluations of enzymatic debridement of burn eschar. Surgery 1973;73:15-22.

14. Pelle MT, Miller OF. Debridement of necrotic eschar with $40 \%$ urea paste speeds healing of residual limbs and avoids further surgery. Arch Dermatol 2001;1371288-1290. 